\title{
The Effect of ePortfolio Satisfaction on Students' Learning Motivation and Internet Self-efficacy
}

\author{
Jeff J.S. Huang \\ Hwa Hsia Institute of Technology \\ Stephen J.-H. Yang \\ Matt C.-W. Chang \\ National Central University
}

\begin{abstract}
This study aims to investigate the effect of e-Portfolio satisfaction on students' learning motivation and Internet self-efficacy toward the use of e-Portfolio. The data collected for this study occurred over 3 months. Participants were 450 students taking the course of common at an university. The counting of 443 questionnaires was received. The findings revealed that there were positive correlations between learning motivation, Internet self-efficacy, and e-Portfolio satisfaction. For gender, the result showed that there were no significant Internet self-efficacy differences between gender. Besides, there were the significant differences in learning motivations and in Internet self-efficacy between the two groups. Furthermore, the multistep regression analysis indicated that the learning motivation was the significant predictor of Internet self-efficacy, and Internet self-efficacy was the significant predictor of e-Portfolio satisfaction. Based on the findings, educators and researchers needed to pay attention to these influences and take these factors into consideration in e-Portfolio. The study concludes by assessing the overall gains and shortcomings of the reform effort toward using the e-Portfolio to help student self-learning.
\end{abstract}

Keyword: e-Portfolio; learning motivation; Internet self-efficacy; e-Portfolio satisfaction

\section{Introduction}

Using technologies to conduct online learning make teaching more versatile, and can also reduce the restriction of traditional teaching. In the past, various skills, personal characteristics, and accumulated knowledge accomplished by students during school time were mostly recorded by papers, or sometimes could not even be recorded by papers (e.g., sounds and videos) (Abrami \& Barrett, 2005). Hence, it seems to be more important to use e-Portfolio to collect students' works in order to present their great efforts, progress, and self-reflection and also to achieve the purpose of sharing.
Past research pointed out that learning motivation is the most important factor affecting learning. Students who have higher learning motivation enhance their learning experience and improve their learning outcomes. Lack of learning motivation can make students less willing to learn and affect their performances (Cole, Feild, \& Harris, 2004; Pintrich \& Groot, 1990). From the above, students' learning motivation is an important part of the learning process in an actual teaching environment. Consequently, this study will incorporate factors of learning motivation to be explored. 
Self-efficacy has been an important factor of affecting learners' learning performances in the learning process (Bandura, 1997). Is the Internet self-efficacy an important factor in affecting learners' learning performances in the learning process? Several research studies have confirmed that the level of learners' Internet self-efficacy could affect their learning outcomes on the Internet (Joo, Bong, \& Choi, 2000; Peng, Tsai, \& Wu, 2006; Thompson, Meriac, \& Cope, 2002; Tsai \& Tsai, 2003), and it could also influence their intention to continue using the Internet (Hsu \& Chiu, 2004; Hsu, Chiu, \& Ju, 2004), perceived usefulness toward the Internet (Liaw, 2008), and perceived ease of use toward the Internet (Wei \& Zhang, 2008). Hence, we found that the Internet self-efficacy played an important role in learning content on the Internet. In terms of our research, investigating learners' Internet self-efficacy is going to be an important issue.

E-Portfolio is an electronic portfolio information system. To construct an information system is important because it requires a lot of money and time investment and many system developers. Hence, assessing whether or not an information system is necessary seems to be quite important. System satisfaction was one of the indicators of assessing an information system (Bailey \& Pearson, 1983; Gelderman, 1998; Ives, Olson, \& Baroudi, 1983; Wang, 2003). In this study, integrating e-Portfolio system into students' learning process and implementing the system were two tasks for the researchers. The students would face a totally different operating flow, such as computer and system operation, Internet usage, and digitizing the papers, etc., and these are all issues that they need to overcome. In addition, students' resistance is one of the obstacles in implementing the system. Owing to system satisfaction could influence users' intentions to use the system (Liaw, 2008; Wang, 2003), and students' e-Portfolio satisfaction is one of the highlights of this study.
According to the above description, we propose the following research questions:

1. Does gender have any significant differences in Internet self-efficacy?

2. What are the influences of the learning motivation, Internet self-efficacy, and e-Portfolio satisfaction in the use of ePortfolio?

3. Are there significant differences in learning motivation and Internet selfefficacy between the experimental and control group?

\section{Literature Review}

\subsection{E-Portfolio}

The main purposes of e-Portfolio are to record students' learning experiences and archives. By collecting these records, the physical evidence of their growth in learning can be reflected upon as they adjust their learning strategies and goals, and to provide a concrete direction for their future development plan. In recent years, e-Portfolios have become more and more important in the education field. For example, in Australia, students in many schools have developed e-Portfolios using readily-accessible presentation or Web-publishing software. Today, using technologies to conduct online learning make teaching more versatile, and can also help reduce the restriction of traditional teaching. So, the e-Portfolio system has become a major self-learning platform that supports self-reflection and sharing of ideas over the Internet. Using e-Portfolio to collect students' works to present their great efforts, progress, and self-reflection is important. Also, such collections of work can achieve the purpose of sharing (Christen \& Hofmann, 2008). The researchers investigated the impact of students' learning motivation, Internet selfefficacy, and e-Portfolio satisfaction toward the use of e-Portfolio in this study. 


\subsection{The Learning Motivation}

Learning motivation is defined as the cause of learners' activities and interests which drives learners to conduct and maintain their learning activities, and is also the internal drive that makes learning activities move toward meeting goals set-up by instructors (Pintrich \& Groot, 1990). By definition, learning motivation would boost learners' learning activities and achieve learning goals established by instructors. In Educational Psychology, learning ability and learning motivation have been seen as two subjective conditions of understanding learners. The learners' learning motivation could affect their learning outcomes directly (Coffin \& MacIntyre, 1999; Cole, et al., 2004). Hence, learning motivation is an important topic in education, and that is why the researchers include learning motivation as one of the research topic.

\subsection{The Internet Self-efficacy}

Internet self-efficacy was extended from the self-efficacy in the social learning theory of Bandura (1997). Self-efficacy refers to one's capabilities in executing some tasks or facing challenges. They can anticipate how much work they could finish or how big the challenge they could face. Learners with low self-efficacy lacked confidence of their capabilities; they would accept but not question the information they received because they were not confident about their capabilities. On the contrary, learners with high self-efficacy had their own learning styles and were confident about their capabilities (Murphy, et al., 1988). Learners' self-efficacy has a correlation with learning performances (Multon, Brown, \& Lent, 1991). Furthermore, the level of learners' self-efficacy could be as an effective predictor on assessing the performance of learning outcomes (Lane, Lane, \& Kypriannou, 2004; Multon, et al., 1991). With respect to Internet self-efficacy, it has been defined as one's assessment of his/her capabilities to use the Internet and accomplish Internet assignments (Eastin \& LaRose, 2000; Tsai \& Tsai, 2003). Users who have no confidence in using the Internet, not satisfied with their Internet skills, or uncomfortable in using of the Internet would be regarded as low Internet selfefficacy learners (Eastin \& LaRose, 2000). Some studies mentioned that Internet selfefficacy would influence intention to the use of certain information systems (Hsu \& Chiu, 2004; Hsu, et al., 2004; Roca, Chiu, \& Martínez, 2006; Wei \& Zhang, 2008), and learners with high Internet self-efficacy were more energetic in using e-learning systems than learners with low Internet self-efficacy. With regard to Web searching, when people with high Internet self-efficacy face difficulties or fail in using the Internet, they would be more likely to confront these setbacks than ones with low Internet self-efficacy and use different strategies to achieve the searching goal (Tsai \& Tsai, 2003). That is, learners with high Internet self-efficacy had better performance than ones with low Internet self-efficacy in implementing network tasks and having their learning outcomes on the Internet affected (Peng, et al., 2006; Tsai \& Tsai, 2003; Wang \& Newlin, 2002; Wu \& Tsai, 2006). Therefore, we know from the above that learners' Internet self-efficacy is an important issue in online learning environment.

\subsection{The e-Portfolio Satisfaction}

Satisfaction refers to an emotional reaction or effect towards a thing, and the same definition is adopted into information system. Bailey \& Pearson (1983) defined the satisfaction as the sum of positive and negative feelings or attitudes. Oliver (1977) proposed that satisfaction is the assessment of emotion as whether system users have the same expectations of the system after using it. Consequently, e-Portfolio satisfaction in this study is de- 
fined as the level of satisfaction after using the e-Portfolio system. User satisfaction was one of the indicators of assessing whether or not an information system is successful (Bailey \& Pearson, 1983; Gelderman, 1998; Ives, et al., 1983; Wang, 2003). Higher user satisfaction denoted that there would be a higher intention to continue using the system and less likely to complain (Delone \& McLean, 2003; Liaw, 2008; Wang, 2003). Thus, in this study, the researchers consider that e-Portfolio satisfac- tion is quite important, and include this variable into the research.

\subsection{The Major Function of e-Portfolio}

In the current study, the researchers developed an e-Portfolio system as the self-learning system. Figure 1 shows the architecture and major functions of the system, respectively include the e-Portfolio homepage, personal portfolio, course forum, profile, friends, and resume.

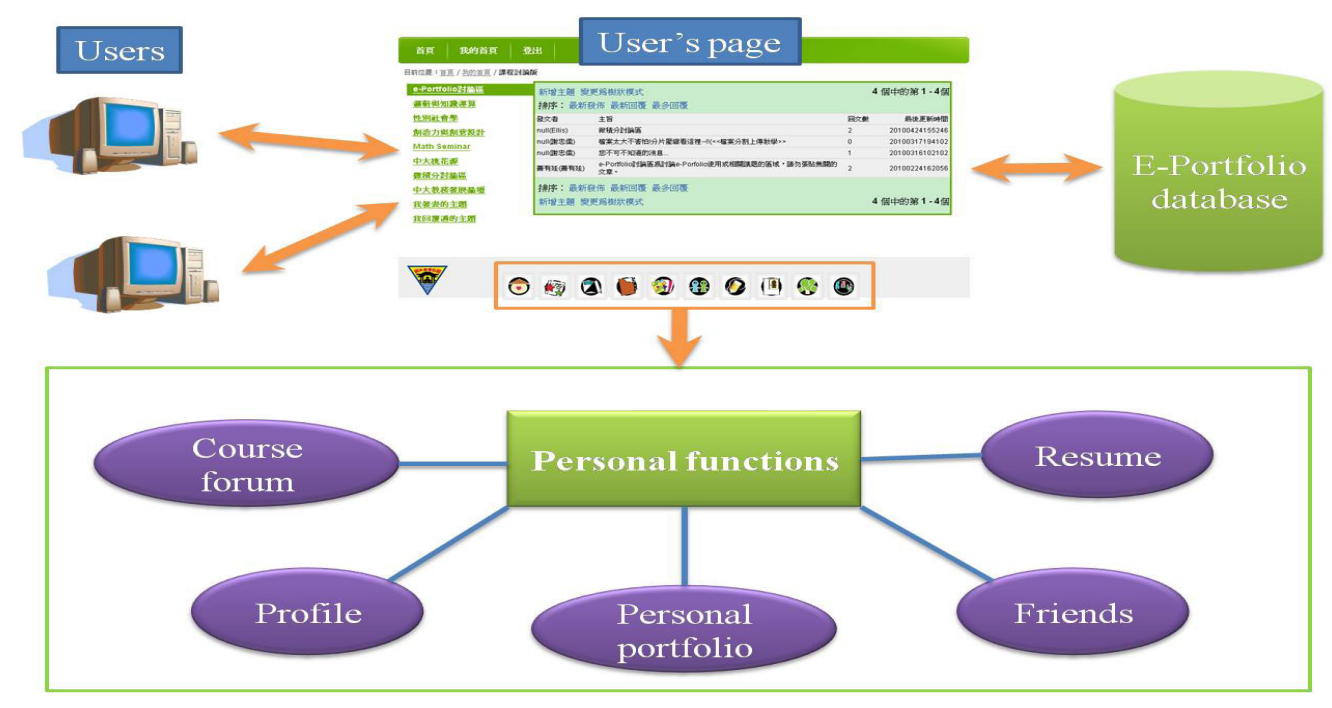

Figure 1. System architecture and major functions.

The e-Portfolio homepage provides the latest topic, news, tag cloud, and login functions, as Figure 2 shows. From this homepage, learners can find the latest topics that were posted, the news of learning information and announcements, and the most popular tags among tag clouds. The personal portfolio can manage personal articles and files, such as adding a new discussion or deleting an old post. The course forum is a powerful learning tool for both students and instructors because it can support interaction and collaboration among students and instructors. The instructors can raise topical discussions in order to enhance group interactions, and promote self reflection among students. The profile function provides the basic information of the user like nicknames, e-mail, etc. The friends function connects the users with friends and others who work, study, and live around them, thus making it easy to access friends' portfolios. The last, the resume function, let learners create personal online resumes. E-Portfolio features are as shown in table 1 and figure 1. 
Table 1. E-Portfolio Platform Functions.

\begin{tabular}{ll}
\hline Feature & Description \\
\hline Users' page & $\begin{array}{l}\text { Including the latest topics, news, forum information which learner can subscribe, and } \\
\text { view friends' newest portfolio. }\end{array}$ \\
The discussion area is open to the campus that contains the curriculum discussion and \\
on-line teaching material. \\
Profile & $\begin{array}{l}\text { Individual's self-introduction, management of personal files, display pictures, etc. } \\
\text { Records student's portfolio, providing uploading of files, pictures, videos, and other } \\
\text { multimedia. }\end{array}$ \\
Friends & $\begin{array}{l}\text { Connects users with friends and others who work, study, and live around them, and } \\
\text { make it easy to access friends' portfolios }\end{array}$ \\
Resume & Write a personal resume, supporting imput from individual's portfolios. \\
\hline
\end{tabular}

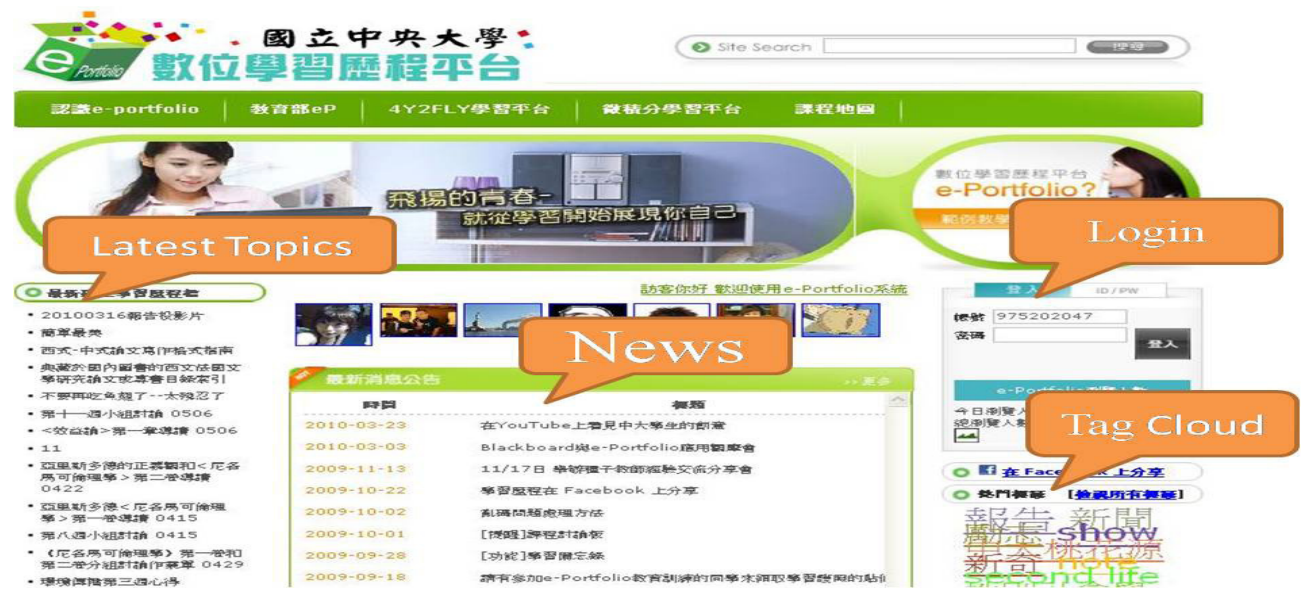

Figure 2. E-Portfolio homepage.

\section{Research Hypothesis}

\subsection{Responding the Research Question 1}

The gender differences in Internet self-efficacy had been regarded as one of the important research topics (Torkzadeh \& Van Dyke, 2002; Tsai \& Lin, 2004; Tsai M.-J. \& Tsai, 2010; Wu \& Tsai, 2006), and till now, this issue has not seen a consistent conclusion yet. Some studies proposed that gender gap had no significant difference in Internet self-efficacy (Torkzadeh \& Van Dyke, 2002; Tsai \& Tsai, 2010). Besides, some research indicated that females had higher Internet self-efficacy than males (Tsai \& Lin,
2004), but others had totally opposite results that the males higher Internet self-efficacy than the females (Wu \& Tsai, 2006). There were many studies that investigated gender differences in Internet self-efficacy, but all with the different results. Today, many students experience access to the network and have similar learning experiences for both boys and girls. The researchers assume that college students will also show no significant gender differences. Therefore, we propose the following research hypothesis:

- H1: Gender has no significant difference in Internet self-efficacy. 


\subsection{Responding the Research Question 2}

Peng, Tsai, \& Wu (2006) mentioned that the Internet self-efficacy was an important factor in influencing students' motivation, interests, and performance at college level. Students' learning motivation would influence their attitudes towards the Internet (Coffin \& MacIntyre, 1999), and attitudes toward the Internet can affect Internet self-efficacy (Wu \& Tsai, 2006). From the literature, we know that there is an inseparable relationship between the Internet self-efficacy and learning motivation, but there was less research investigating the relationship between these two factors. Therefore, this research would investigate the relationship between learning motivation and Internet selfefficacy of students using e-Portfolio, and we propose the following research hypothesis:

$\mathrm{H} 2$ : The learning motivation is a significant predictor of Internet self-efficacy.

The computer self-efficacy would influence students' satisfaction in online learning process (Wu, Tennyson, \& Hsia, 2010), which also means that computer self-efficacy has certain influence on information systems. Some literature also indicate that Internet self-efficacy has a significant correlation with users' satisfaction toward using the system to conduct learning. Roca, Chiu, \& Martínez (2006) proposed that Internet self-efficacy has an indirect correlation with system satisfaction. Sun, Tsai, Finger, Chen, \& Yeh (2008), Shu-Sheng Liaw, et al (2007), and Chu \& Chu, (2010) focus on this issue and propose the hypothesis. The results indicated that there is a significant correlation between Internet self-efficacy and system satisfaction. Moreover, from the research of Liaw (2008), Internet self-efficacy is the significant predictor of system satisfaction. In an era that Web-based learning has become more prevalent, the research about Internet self-efficacy and system satisfaction from users' points of view has become more important. In this study, the researchers use the term "e-Portfolio satisfaction" to assess the students' satisfaction toward the use of e-Portfolio. Therefore, the research hypothesis for this topic is:

H3: Internet self-efficacy is a significant predictor of e-Portfolio satisfaction.

\subsection{Responding the Research Question 3}

The students in this study had been divided into two groups, the experimental group (e.g., e-Portfolio users) and the control group (e.g., non-users). The students in the experimental group were well-trained in the use of an e-Portfolio system and actually operated it in class with the teachers; so they were familiar with the system operation. One of the central issues in this study is whether or not the learning motivation and Internet self-efficacy have significant differences between students in the experimental and control groups. Therefore, the researchers propose the following research hypotheses:

H4: There are the significant differences in learning motivation between the experimental group and the control group.

- H5: There are the significant differences in Internet self-efficacy between the experimental group and the control group.

\section{Methodology}

\subsection{Participants}

This study focused on the relationships among learners' learning motivation, Internet self-efficacy, and system satisfaction, by investigating the impact of the above three factors on the use of e-Portfolio. The subjects were college students enrolled at a university in Taoyuan, Taiwan.

The data collection consisted of a pilot study and a written questionnaire. Data col- 
lection took place between February 2010 and April 2010. Before testing, we conducted training for using the e-Portfolio system in September 2009. And then we conducted a pilot questionnaire survey in the December 2009. A total 125 questionnaires were received. The researchers analyzed the pilot test results and made some modifications.

In February 2010, the researchers conducted a second e-Portfolio system of training, and at the end of April 2010, issued a formal questionnaire survey to participants, in which 443 questionnaires were received. A total of 277 male students $(62.5 \%)$ and 166 female students $(37.5 \%)$ returned the survey. The researchers then divided students into two groups: the experimental group and the control group. The experimental group was trained in using our e-Portfolio system before the semester, and later when the system was incorporated into the teaching of the classes. Thus, students were familiar with the system, and included 296 students $(66.8 \%)$. On the contrary, the students in the control group adopted traditional teaching methods and were non-users of e-Portfolio, counting at 147 students (33.2\%).

\subsection{Factor Analysis}

A 7-point Likert scale ranging from 1 (strongly disagree) to 7 (strongly agree) was developed for the measurement. For the purpose of understanding the structure of the items in learning motivation, the researchers utilized the principal component analysis for extraction method and Kasier normalization for the rotation method of varimax. There were three principles of item deletion: (1) the eigenvalues need over 1 for extraction factor; (2) deleting items was based on the relevant factor greater than 0.5 and the non-relevant factor less than 0.5 ; and (3) abandon the factor which it was less than three items. No items needed to be deleted from the initial learning motivation questionnaire.
The cronbach' $\alpha$ for the two factors of the learning motivation, respectively were 0.74 (Intrinsic goal orientation, 4 items) and 0.76 (Extrinsic goal orientation, 4 items). The cronbach' $\alpha$ of the whole learning motivation questionnaire is 0.73 and the total variance explained is $57.76 \%$. Therefore, the two factors of learning motivation can be considered well sufficiently reliable for researching students' learning motivation.

The same process was used to understand the structure of factors of the Internet self-efficacy questionnaire. There was reduced one item from the initial 22 items, and then divided into three factors: General Internet self-efficacy, Communicative Internet self-efficacy, and Web-learning Internet self-efficacy. The cronbach' $\alpha$ for the three factors of Internet self-efficacy, respectively were 0.91 (General Internet self-efficacy, 10 items), 0.90 (Communicative Internet self-efficacy, 4 items), and 0.89 (Web-learning Internet self-efficacy, 7 items). The cronbach' $\alpha$ of the whole Internet self-efficacy questionnaire is 0.93 and the total variance explained is $62.97 \%$. Therefore, the three factors of Internet self-efficacy can be considered well sufficiently reliable for researching students' Internet self-efficacy.

The same process was used to understand the structure of the factors of the e-Portfolio satisfaction questionnaire. The original 12 item questionnaire was reduced to 8 items, with two factors. The first one is Function satisfaction and the other is Community satisfaction. The cronbach' $\alpha$ for the two factors of the e-Portfolio satisfaction, respectively were 0.83 (Function satisfaction, 4 items) and 0.85 (Community satisfaction, 4 items). The cronbach' $\alpha$ of the whole e-Portfolio satisfaction questionnaire is 0.87 and the total variance explained is $68.75 \%$. Therefore, the two factors of the e-Portfolio satisfaction can be considered well sufficiently reliable for researching students' e-Portfolio satisfaction. 


\section{Results}

\subsection{Correlations among learning motivation, Internet self-efficacy and e-Portfolio satis- faction}

Table 2 shows the means, standard deviations, and Pearson correlation coefficients among the questionnaire scales. The relationships among the three main scales are significantly positively correlated with each other.

In Table 2, we can find that the three factors in Internet self-efficacy had higher correlations to the intrinsic goal orientation than the extrinsic goal orientation. The general Internet selfefficacy $(r=.51, p<.01)$ has the highest correlation to the intrinsic goal orientation in the
Internet self-efficacy, Web-learning Internet self-efficacy $(r=.50, p<.01)$ was the second, and then communicative Internet self-efficacy $(r=.37, p<.01)$. With special reference to the e-Portfolio satisfaction, the two factors had better correlations to the Internet self-efficacy, with three factors, respectively Web-learning Internet self-efficacy $(r>.43, p<.01)$ was the highest, communicative Internet self-efficacy $(r>.32, p<.01)$ was the second, and general Internet self-efficacy $(r>.39, p<.01)$ was the last. It seemed that students with higher learning motivation tended to display more positive perception toward Internet self-efficacy, as well as higher Internet self-efficacy the better e-Portfolio satisfaction the students had.

Table 2. Descriptive Statistics, Sorrelation among Study Variables $(n=296)$

\begin{tabular}{lcccccccc}
\hline Variables & Means & $S D$ & $(1)$ & $(2)$ & $(3)$ & $(4)$ & $(5)$ & $(6)$ \\
\hline Learning motivation & & & & & & & & \\
$\quad$ (1)Intrinsic goal orientation & 5.24 & 0.83 & & & & & & \\
(2)Extrinsic goal orientation & 5.01 & 0.92 & $.26^{* *}$ & & & & & \\
Internet self-efficacy & & & & & & & \\
(3)General ISE & 5.36 & 0.88 & $.51^{* *}$ & $.30^{* *}$ & & & & \\
(4)Communicative ISE & 5.07 & 0.95 & $.37^{* *}$ & $.27^{* *}$ & $.70^{* *}$ & & & \\
(5)Web-learning ISE & 5.19 & 0.88 & $.50^{* *}$ & $.30^{* *}$ & $.78^{* *}$ & $.60^{* *}$ & & \\
E-Portfolio satisfaction & & & & & & & & \\
(6)Function satisfaction & 4.88 & 0.91 & $.28^{* *}$ & $.13^{*}$ & $.40^{* *}$ & $.32^{* *}$ & $.43^{* *}$ & \\
(7)Community satisfaction & 4.64 & 0.86 & $.27^{* *}$ & $.13^{*}$ & $.39^{* *}$ & $.36^{* *}$ & $.45^{* *}$ & $.69^{* *}$ \\
\hline
\end{tabular}
Note: "p<.05;" $p<.01$

\subsection{T-test for gender and group differences}

Independent-samples T-test was utilized to test the significance of the difference between genders, and the same method examined the group differences. The results are presented in Table 3 and Table 4. Among the variables examined in the study, there was no significance at the level of .05. Thus, no significant differences between males and females in general Internet self-efficacy, communicative Internet self-efficacy, and Web-learning Internet selfefficacy existed. But, special attention should be paid to general Internet self-efficacy $(t=$ $-1.96, p=0.05)$ when the .10 level of significance was used. 
The students using the e-Portfolio system were grouped into the experimental group, and the other non-users were grouped into the control group. Independent-samples T-test was shown in Table 4. Excluding extrinsic goal orientation $(t=1.05, p=0.29)$, the others were significant, respectively were intrinsic goal orientation $(t=2.82, p=0.01)$, general Internet self-efficacy $(t=2.87, p<0.01)$, communicative Internet self-efficacy $(t=3.27, p<0.01)$, and Web-learning Internet self-efficacy $(t=$ $4.91, p=0.00)$. This finding could show that the experimental group has a higher intrinsic goal orientation and higher Internet self-efficacy of all three factors than the control group.

Table 3. Gender Comparisons on the Scales of Learning Motivation and Internet Self-efficacy Survey

\begin{tabular}{lllll}
\hline & Male (mean, SD) & Female (mean, SD) & $t$ value & Sign. \\
\hline Internet self-efficacy & & & & \\
General ISE & $5.28(0.91)$ & $5.49(0.82)$ & -1.96 & $0.05($ n.s. $)$ \\
Communicative ISE & $5.06(0.96)$ & $5.10(0.95)$ & -0.39 & 0.69 (n.s.) \\
Web-learning ISE & $5.14(0.91)$ & $5.27(0.81)$ & -1.25 & 0.21 (n.s.) \\
\hline
\end{tabular}

n.s.: not significant.

Table 4. Groups Comparisons on the Scales of Learning Motivation and Internet Self-efficacy Survey

\begin{tabular}{lllll}
\hline & $\begin{array}{l}\text { Experimental group } \\
\text { (mean, SD) }\end{array}$ & $\begin{array}{l}\text { Control group } \\
\text { (mean, SD) }\end{array}$ & $t$ value & Sign. \\
\hline Learning motivation & & & & \\
$\quad$ Intrinsic goal orientation & $5.24(0.83)$ & $4.99(0.89)$ & 2.89 & $0.00^{* *}$ \\
Extrinsic goal orientation & $5.09(0.92)$ & $4.98(1.13)$ & 1.05 & 0.29 (n.s.) \\
Internet self-efficacy & & & & \\
General ISE & $5.36(0.88)$ & $5.07(1.07)$ & 2.87 & $0.00^{* *}$ \\
Communicative ISE & $5.07(0.95)$ & $4.69(1.24)$ & 3.27 & $0.00^{* *}$ \\
Web-learning ISE & $5.19(0.88)$ & $4.66(1.15)$ & 4.91 & $0.00^{* * *}$ \\
\hline
\end{tabular}

Note: ${ }^{*} p<.05 ;{ }^{* *} p<.01 ;{ }^{* * *} p<.001$

\subsection{Stepwise Multiple Regression Analysis}

For the purpose of testing research hypothesis 2 and 3, the stepwise multiple regression analysis was proposed. The result of regression analysis is shown in Table 5. For the research hypothesis 2 , the results revealed that the learning motivation $(\mathrm{t}=10.67, \mathrm{p}<0.001)$ was the significant predictors of Internet self-efficacy, and total variance explained of Internet selfefficacy was $28 \%$. The researchers then uti- lized the factors of the learning motivation as the independent variables and the factors of the Internet self-efficacy as the dependent variable, as Table 5 shows. Intrinsic goal orientation $(t=$ $8.97, p<0.001)$ and extrinsic goal orientation $(t=3.67, p<0.001)$ were the significant predictors of general Internet self-efficacy, with the $29 \%$ contribution. In addition, the independent variables of intrinsic goal orientation $(t=$ 5.77, $p<0.001)$ and extrinsic goal orientation $(t=3.40, p<0.01)$ could predict the communi- 
cative Internet self-efficacy, with the $17 \%$ contribution. Finally, intrinsic goal orientation $(t=$ $8.80, p<0.001)$ and extrinsic goal orientation $(t=3.56, p<0.001)$ were the significant pre- dictors of Web-learning Internet self-efficacy, and $28 \%$ of Web-learning Internet self-efficacy was explained. Thus, the research hypothesis 2 was supported.

Table 5. The Result of Predicted Path Relationships

\begin{tabular}{lllllll}
\hline Outcome & Predictors & B & S.E. & $\beta$ & $t$-value & $R^{2}$ \\
\hline Internet self-efficacy & Learning motivation & 0.64 & 0.06 & 0.53 & $10.67^{* * *}$ & 0.28 \\
General ISE & Intrinsic goal orientation & 0.48 & 0.05 & 0.46 & $8.97^{* * *}$ & \\
& Extrinsic goal orientation & 0.18 & 0.05 & 0.19 & $3.67^{* * *}$ & 0.29 \\
Communicative ISE & Intrinsic goal orientation & 0.36 & 0.06 & 0.32 & $5.77^{* * *}$ & \\
& Extrinsic goal orientation & 0.19 & 0.06 & 0.19 & $3.40^{* *}$ & 0.17 \\
Web-learning ISE & Intrinsic goal orientation & 0.47 & 0.05 & 0.45 & $8.80^{* * *}$ & \\
E-Portfolio satisfaction & Extrinsic goal orientation & 0.17 & 0.05 & 0.18 & $3.56^{* * *}$ & 0.28 \\
Function Satisfaction & Internet self-efficacy & 0.48 & 0.05 & 0.48 & $9.32^{* * *}$ & 0.23 \\
& Web-learning ISE & 0.31 & 0.09 & 0.30 & $3.59^{* * *}$ & \\
Community Satisfaction & General ISE & 0.18 & 0.09 & 0.17 & $2.06^{*}$ & 0.20 \\
& Web-learning ISE & 0.36 & 0.06 & 0.37 & $5.62^{* * *}$ & \\
& Communicative ISE & 0.12 & 0.06 & 0.14 & $2.08^{*}$ & 0.21 \\
\hline
\end{tabular}

Note: ${ }^{*} p<.05 ;{ }^{* *} p<.01 ;{ }^{* * *} p<.001$

For research hypothesis 3 , Table 5 showed the Internet self-efficacy $(t=9.32, p<0.001)$ was the significant predictor of e-Portfolio satisfaction, and total explained variance of Internet self-efficacy was $23 \%$. In more detail, Web-learning Internet self-efficacy $(t=3.59, p$ $<0.001)$ and general Internet self-efficacy $(t=$ $2.06, p<0.05)$ were the significant predictors of function satisfaction, with the $20 \%$ contribution. In addition, Web-learning Internet self-efficacy $(t=5.62, p<0.001)$ and communicative Internet self-efficacy $(t=2.08, p<0.05)$ were the significant predictors of community satisfaction, and $21 \%$ of community satisfaction was explained. Thus, the research hypothesis 3 was supported.

\section{Discussions}

In this study, we used the factor analysis for testing the reliability of the questionnaire, analyzing the correlations among variables, independent-sample T-test for gender differences and group differences (experimental and control group), and the stepwise multiple regression analysis for the relationships among variables.

\subsection{Gender Differences in Internet Self-efficacy}

In past research, there was no confirmed result in gender differences of Internet selfefficacy (Torkzadeh \& Van Dyke, 2002; Tsai \& Lin, 2004; Tsai \& Tsai, 2010; Wu \& Tsai, 
2006). In our research, the university students had no significant difference between genders in Internet self-efficacy, as shown in Table 3. This finding was different from previous research (Peng, et al., 2006; Tsai \& Lin, 2004; Wu \& Tsai, 2006). Tsai and Lin (2004) indicated that female students took a dominant position than male students at the senior high school level. The explanation may be that the students were in single-sex classes, and females were probably compared with each other in their confidence toward use of the Internet. However, the students of this study were not in single-sex classes and at a university level, with the result that the females with higher Internet self-efficacy did not exist. In addition, the male students were found more confident toward Internet self-efficacy at a university level in other research studies (Peng, et al., 2006; Wu \& Tsai, 2006), but this finding was not found in this research. Reason might be that Internet skills are basic skills to all university students, and female students may spend more time on the Internet than before, with the result that males with higher Internet self-efficacy did not exist in current study.

The genders we found in our study had the same Internet self-efficacy, and that was the same as Tsai and Tsai (2010) mentioned. At the university, students have more and more opportunities to participate in online courses and e-learning systems, like this e-Portfolio system. Students in this study were enthusiastic in using e-Portfolio systems. Barker (2006) proposed that the Internet is the most frequently used media for e-Portfolio, and our system provides discussion with peers and directors, uploading capabilities of homework, making friends, and composing online resume, etc. Therefore, there was no gender difference in Internet self-efficacy for this study, with results being the opposite in that the gender gap was narrowed.

\subsection{Stepwise Multiple Regression Analysis among Variables}

From Table 2, the researchers found that there were correlations among all of the factors in learning motivation and in Internet selfefficacy, which confirmed to what Peng, et al. (2006) mentioned. Furthermore, the intrinsic goal orientation and extrinsic goal orientation in the learning motivation were the significant predictors of the factors in Internet self-efficacy in the e-Portfolio environment (shown in Table 5). As a result, we can say that learning motivation had a positive correlation and could be an effective predictor to Internet self-efficacy; students with higher learning motivation tended to display more positive perception in Internet self-efficacy. It might be said that students with higher learning motivation might find learning interesting in e-Portfolio, thus leading to further use of e-Portfolio. Thus, students would then have higher Internet self-efficacy.

The finding coincided with those of ShuSheng Liaw (2007) and Sun, et al. (2008), and there were correlations between Internet selfefficacy and e-Portfolio satisfaction (shown in Table 2). Moreover, the regression analysis corroborated with Liaw (2008), and the Internet self-efficacy was the significant predictor of the e-Portfolio satisfaction in e-Portfolio. The Web-learning Internet self-efficacy was a key factor that predicted function satisfaction and community satisfaction (Table 5 ). Consequently, Internet self-efficacy had a positive correlation and could be an effective predictor to e-Portfolio satisfaction; students with higher Internet self-efficacy tended to show more positive perception toward e-Portfolio satisfaction, and Web-learning Internet self-efficacy played an important role in influencing e-Portfolio satisfaction. We could say that students with higher Internet self-efficacy would have more confidence in using e-Portfolio, and be less likely to reject the system. Thus, students would then have higher e-Portfolio satisfaction. 


\subsection{Groups Differences in Intrinsic Goal Ori- entation of Learning Motivation and Inter- net Self-efficacy}

Finally, the researchers compared the difference between the experimental group and the control group, and the e-Portfolio system users and non-users respectively. Table 4 showed that every factor had a significant difference between groups except for the extrinsic goal orientation. e-Portfolio system can upgrade students' intrinsic goal orientation for several reasons. First, e-Portfolio is the online self-learning platform, providing functions for learners to record their learning processes and learning achievements, sharing their learning experiences and goals, reflecting on the learning, and discussing with peers and instructors that all contributes to learning (Ahn, 2004; Barrett, 2001). Second, learning in an e-Portfolio environment is unlike learning in the traditional classroom. It offers diverse learning for students, with the result of increasing students' interest in learning. Finally, traditional teaching is teacher-oriented, and e-Portfolio transforms the mode to student-oriented, that is, the students plan their own learning. Besides, e-Portfolio system also upgrades the students' Internet self-efficacy. The e-Portfolio users were going to have more Web-learning experience than non-users, and that would increase their confidence toward the Internet.

\section{Conclusions}

Several findings are concluded from the current study. First, the researchers found that gender differences in Internet self-efficacy were not present among university students. Further, learning motivation was a significant predictor of the Internet self-efficacy and that Internet self-efficacy could significantly predict the e-Portfolio satisfaction. Finally, the intrinsic goal orientation of the learning motivation and Internet self-efficacy were signifi- cantly different between e-Portfolio system users and non-users.

The findings from this study have following educational implications for e-Portfolio learning.

1. According to previous research, intrinsic goal orientation and Internet self-efficacy would affect academic performance (Cole, et al., 2004; Joo, et al., 2000; Peng, et al., 2006; Pintrich \& Groot, 1990; Thompson, et al., 2002). As revealed in this study, hypothesis 5 was supported. It means that the e-Portfolio system can upgrade students' intrinsic goal orientation and Internet self-efficacy.

2. As revealed in this study, hypothesis 2 was supported. The intrinsic goal orientation and extrinsic goal orientation in the learning motivation were significant predictors of the factors in Internet selfefficacy in e-Portfolio environments. This means that students with higher learning motivation will tend to display more positive perceptions toward Internet selfefficacy. In other words, it might be said that students with higher learning motivation might have encouraged their learning interest to use the e-Portfolio to help with self learning, and thus, increasing the overall use of e-Portfolio.

Given the findings mentioned above, the researchers suggest that instructors incorporate e-Portfolio systems into their classroom instruction to encourage students to take control of their learning and self-evaluation processes. Future research could be aimed toward investigating academic performance of e-Portfolio users as compared to others, or investigate external variables that may influence the success of e-Portfolio users. 


\section{References}

Abrami, P. C., \& Barrett, H. (2005). Directions for Research and Development on Electronic Portfolios. Canadian Journal of Learning and Technology, 31(3), Fall / automne, 2005.

Ahn, J. (2004). Electronic Portfolios: Blending Technology, Accountability \& Assessment. T.H.E. Journal, 31(9), 12 - 18.

Bailey, J. E., \& Pearson, S. W. (1983). Development of a Tool for Measuring and Analyzing Computer User Satisfaction. Management Science, 29(5), 530-545.

Bandura, A. (1997). Self-efficacy: The exercise of control: New Work: W.H. Freeman.

Barker, K. C. (2006). Environmental scan: Overview of the ePortfolio in general and in the workplace specifically. Retrieved on October 20, 2006 from http://www.FuturEd.com.

Barrett, H. C. (2001). Electronic portfolios. In A. Kovalchick \& K. Dawson (Eds.), Educational technology: An encyclopedia. Santa Barbara, CA: ABC-Clic.

Chang, C.-C. (2001). A study on the evaluation and effectiveness analysis of web-based learning portfolio (WBLP). British Journal of Educational Technology, 32(4), 435 $-458$.

Christen, A., \& Hofmann, M. (2008). Implementation of E-Portfolio in the First Academic Year at the University of Teacher Education St. Gallen. International Journal of Emerging Technologies in Learning, 3(1), 6-10.

Chu, R. J., \& Chu, A. Z. (2010). Multi-level analysis of peer support, Internet self-efficacy and e-learning outcomes - The contextual effects of collectivism and group potency. Computers \& Education, 55(1), 145-154.

Coffin, R. J., \& MacIntyre, P. D. (1999). Motivational influences on computer-related affective states. Computers in Human Behavior, 15(5), 549-569.
Cole, M. S., Feild, H. S., \& Harris, S. G. (2004). Student Learning Motivation and Psychological Hardiness: Interactive Effects on Students' Reactions to a Management Class. Academy of Management Learning and Education, 3(1), 64-85.

Delone, W. H., \& McLean, E. R. (2003). The DeLone and McLean Model of Information Systems Success: A Ten-Year Update. J. Manage. Inf. Syst., 19(4), 9-30.

Eastin, M. S., \& LaRose, R. (2000). Internet Self-Efficacy and the Psychology of the Digital Divide. Journal of Computer-Mediated Communication, 6(1), 2000.

Gelderman, M. (1998). The relation between user satisfaction, usage of information systems and performance. Information \& Management, 34(1), 11-18.

Hsu, M.-H., \& Chiu, C.-M. (2004). Internet self-efficacy and electronic service acceptance. Decision Support Systems, 38(3), 369-381.

Hsu, M.-H., Chiu, C.-M., \& Ju, T.-L. (2004). Determinants of continued use of the WWW: an integration of two theoretical models. Industrial Management \& Data Systems, 104(9), 766-775.

Hunt, H. K. (1977). CS/D-Overview and Future Research Directions. In H. K. Hunt (Ed.), Conceptualization and Measurement of Consumer Satisfaction and Dissatisfaction. Cambridge, MA: Marketing Science Institute, 459-460.

Ives, B., Olson, M. H., \& Baroudi, J. J. (1983). The Measurement of User Information Satisfaction. Communication of the ACM, 26(10), 785-793.

Joo, Y.-J., Bong, M., \& Choi, H.-J. (2000). Self-efficacy for self-regulated learning, academic self-efficacy, and internet selfefficacy in web-based instruction. Educational Technology Research and Development, 48(2), 5-17.

Lane, J., Lane, A. M., \& Kypriannou, A. (2004). Self-efficacy, self-esteem and their impact 
on academic performance. Social Behavior and Performance, 32(3), 247-256.

Liaw, S.-S. (2008). Investigating Students' Perceived Satisfaction, Behavioral Intention, and Effectiveness of E-Learning: A Case Study of the Blackboard System. Computers \& Education, 51(2), 864-873.

Liaw, S.-S., Huang, H.-M., \& Chen, G.-D. (2007). Surveying instructor and learner attitudes toward e-learning. Computers \& Education, 49(4), 1066-1080.

Multon, K. D., Brown, S., \& Lent, R. (1991). Relation of Self-Efficacy Beliefs to Academic Outcomes: A Meta-Analytic Investigation. Journal of Counseling Psychology, 38(1), 30-38.

Murphy, C. A., \& et al. (1988). Assessment of Computer Self-Efficacy: Instrument Development and Validation. ERIC Documanet No. ED 307317.

Peng, H., Tsai, C.-C., \& Wu, Y.-T. (2006). University Students' Self-Efficacy and Their Attitudes Toward the Internet: The Role of Students' Perceptions of the Internet. Educational Studies, 32(1), 73-86.

Pintrich, P. R., \& Groot, E. V. D. (1990). Motivational and Self-Regulated Learning Components of Classroom Academic Performance. Journal of Educational Psychology, 82(1), 33-40.

Regina Ju-Chun Chu, Hsiu-Ling Chen, ChiaChun Lin, \& Lee, H.-Y. (2008). Learning Influences of Family Support and Selfdirected Learning upon the Internet Selfefficacy of Middle Aged and Old Adults. In Technology Enhanced Learning Conference 2008. Hanoi, Vietnam.

Roca, J. C., Chiu, C.-M., \& Martínez, F. J. (2006). Understanding e-learning continuance intention: An extension of the Technology Acceptance Model. International Journal of Human-Computer Studies, 64(8), 683-696.

Sun, P.-C., Tsai, R. J., Finger, G., Chen, Y.-Y., $\&$ Yeh, D. (2008). What drives a successful
e-Learning? An empirical investigation of the critical factors influencing learner satisfaction. Computers \& Education, 50(4), 1183-1202.

Thompson, L., Meriac, J., \& Cope, J. (2002). Motivating Online Performance: The Influences of Goal Setting and Internet SelfEfficacy. Social Science Computer Review, 20(2), 149-160.

Torkzadeh, G., \& Van Dyke, T. P. (2002). Effects of training on Internet self-efficacy and computer user attitudes. Computers in Human Behavior, 18(5), 479-494.

Tsai, C.-C., \& Lin, C.-C. (2004). Taiwanese Adolescents' Perceptions and Attitudes regarding the Internet: Exploring Gender Differences. Adolescence, 39(156), 725-734.

Tsai, M.-J., \& Tsai, C.-C. (2003). Information Searching Strategies in Web-Based Science Learning: The Role of Internet Self-Efficacy. Innovations in Education and Teaching International, 40(1), 43-50.

Tsai, M.-J., \& Tsai, C.-C. (2010). Junior high school students' Internet usage and self-efficacy: A re-examination of the gender gap. Computers \& Education, 54(4), 1182-1192.

Wang, A. Y., \& Newlin, M. H. (2002). Predictors of web-student performance: the role of self-efficacy and reasons for taking an on-line class. Computers in Human Behavior, 18(2), 151-163.

Wang, Y.-S. (2003). Assessment of learner satisfaction with asynchronous electronic learning systems. Information \& Management, 41(1), 75-86.

Wei, L., \& Zhang, M. (2008). The impact of Internet knowledge on college students' intention to continue to use the Internet. Information Research, 13(3), 348.

Wu, J.-H., Tennyson, R. D., \& Hsia, T.-L. (2010). A study of student satisfaction in a blended e-learning system environment. Computers \& Education, 55(1), 155-164.

Wu, Y.-T., \& Tsai, C.-C. (2006). University Students' Internet Attitudes and Internet 
Self-Efficacy: A Study at Three Universities in Taiwan. CyberPsychology \& Behavior, 9(4), 441-450.

\section{Acknowledgements}

This work is supported by National Science

Council, Taiwan under grants NSC 100-2511S-146 -001, NSC98-2511-S-008-006-MY3, NSC98-2511-S-008-007-MY3, NSC99-2511S-008-006-MY3, and the Research Center for Science \& Technology for Learning of the University System of Taiwan. 


\section{Contact the Authors}

\section{Jeff J.S. Huang}

Hwa Hsia Institute of Technology

Taiwan

Email: Jeff@cchwh.edu.tw

Stephen J.-H. Yang

National Central University

Taiwan

Email: jhyang@csie.ncu.edu.tw

\section{Matt C. $-W$. Chang}

National Central University

Taiwan

Email: 3524011@cc.ncu.edu.tw 